\title{
Smoking on hospital grounds and the impact of outdoor smoke-free zones
}

Amanda L Nagle, Margot J Schofield, Sally Redman

\begin{abstract}
Objectives-To describe the type and location of smokers on the grounds of smoke-free public hospitals and to observe the impact of introducing smokefree signs in outdoor areas of the hospital grounds.
\end{abstract}

Design-Observation study of outdoor smoking behaviour before and after the introduction of outdoor smoke-free signs at one hospital (H1) and at the same two time periods at a nearby control hospital (H2), which already had some outdoor smoke-free signs at Time 1 .

Setting-The John Hunter Hospital (H1) in Newcastle, Australia and a nearby control hospital, Maitland Hospital (H2) in 1991.

Subjects-All people in defined outdoor sites of the two hospitals on seven randomly selected days over two weeks before and after the policy change were coded as either "smoker" or "nonsmoker" and as either "staff", "patient", or "visitor". The number of smokers observed in each site was measured as a proportion of all smokers observed on the grounds of that hospital.

Intervention-Introduction of outdoor smoke-free zones and signs at $\mathrm{H1}$.

Results-Less than $10 \%$ of observed outdoor smokers in both hospitals were patients, $\mathbf{4 0 \%}$ were visitors, and more than $50 \%$ were staff. Of outdoor smokers, $82 \%$ were observed less than $10 \mathrm{~m}$ from entrances to the hospital building at time 1 . After the introduction of signs in $\mathrm{H1}$, a 4-percentage point decrease $(P<0.05)$ occurred in the percentage of smokers observed in smoke-free zones at time 2 (from $32 \%$ to $28 \%$ ), compared with a 2-percentage point decrease $(\mathbf{P}>0.05$ at time 2 in $\mathrm{H} 2$ (from $48 \%$ to $46 \%$ ).

Discussion-This observation study of smoking behaviour in hospital grounds highlights the need to reduce smoking among staff and visitors near hospital entrances. Specific strategies are discussed, which are likely to enhance compliance and hence enable the effective introduction of smoke-free policies on hospital grounds.

(Tobacco Control 1996;5:199-204)

Keywords: smoking policy; hospital; smoke-free areas

\section{Introduction}

As important and highly visible healthcare institutions, hospitals have a responsibility and a leadership role in developing and implementing smoke-free policies. ${ }^{1-4}$ The proc $\stackrel{5}{-}$ ess of establishing smoke-free hospitals ha $\vec{\rho}$ spanned two decades and has followed $\overrightarrow{\mathrm{a}}$ steady, if somewhat slow, series of ree definitions as more credible medical infor mation and greater social acceptability of the rights of non-smokers emerged. ${ }^{5}$ Early efforts at smoking control within hospitals began withe the elimination of tobacco sales on the premises $^{16}$ and the introduction of smoke-free wards and a few designated smoke-free area inside the buildings during the late 1970 s and early 1980s. ${ }^{4}$ A 1978 survey found that onl\$ $42 \%$ of hospitals surveyed in the United State had any anti-smoking regulations and only $21 \%$ prohibited smoking at meetings. ${ }^{4}$ Aso evidence of the effects of passive smoking became more prevalent throughout the 1980s culminating in the release in 1986 of the US Surgeon General's Report, legislation in 39 states in America required the introduction of smoking restrictions in hospitals. ${ }^{4}$ These smok ing restrictions generally included all but a fewo lounges or cafeterias inside the hospitaP buildings. ${ }^{2}$ A 1988 hospital survey in the United States found that $90 \%$ of hospitals had. some form of internal smoking restriction. ${ }^{7}$

The move towards totally smoke-free hospi tal buildings started in the United States, in the latter part of the 1970s. A survey in 1978 foun that less than $1.2 \%$ of randomly selected hospitals in the United States had a tota? smoking ban inside hospital buildings, ${ }^{8}$ and 109 years later in 1988 a survey found that still les than $8 \%$ of hospitals surveyed had totally smoke-free buildings. ${ }^{9}$ In 1991, the Joint Como mission on Accreditation of Healthcar Organizations (JCAHO) issued a standarc requiring acute care hospitals to be totall smoke-free effective January $1992 .{ }^{10}$ In? Australia, legislation was introduced in 1988 N in New South Wales (NSW), which required total prohibition of smoking by all staff? patients, and visitors, in all hospital buildingeo and vehicles. ${ }^{11}$ The impact of this legislation was to dramatically increase the pace of change in tobacco control within Australia.

Compliance with smoke-free bans withiro hospital buildings has generally been reported as good to excellent. ${ }^{110}$ Surveys of both staff and patients have found widespread accept ability of smoke-free policies within hospi-o tals, ${ }^{1213}$ and such policies have been found to reduce environmental tobacco smoke ande smoking inside hospital buildings. ${ }^{14-16}$ One national on-site inspection of more than 3000 American hospitals in 1993 found that $95.6 \%$ were complying with the JCAHO smoke-free 
hospital standard. ${ }^{10}$ Another 1993 American study found that $65 \%$ of over 1000 American hospitals were complying with the standard within 16 months of its introduction. ${ }^{17}$ While the American data ${ }^{18}$ suggest there is good compliance with indoor smoke-free policies in hospitals, no research has been undertaken on this issue in Australian hospitals although it is likely that results are similar to those in the United States.

Recently a few hospitals in the United States, Japan, and Australia have undertaken initiatives aimed at the gradual implementation of totally smoke-free hospital sites (that is, restrictions which include parts or all of the grounds outside the buildings). For example, the Mayo Clinic, Rochester, Minnesota, in its 1987 smoke-free policy implementation, included the grounds of the medical facility as a smoke-free area. Hurt and colleagues, however, reported problems at the Mayo Clinic with people smoking "on the fringes of the medical center grounds [which] have led to complaints by neighbouring businesses". ${ }^{18}$ An extensive literature search has revealed no studies that provide data on smoking behaviour on the grounds of hospitals.

The current study was undertaken in the Hunter region of NSW, Australia, and used direct observations to describe smoking behaviour on the grounds of hospitals. The first aim of the study was to describe, at time 1, the number and percentage of outdoor smokers who were staff, visitors, or patients and the location of smoking within the grounds. The second aim of the study was to determine whether the introduction of outdoor smokefree signs in one hospital was effective in reducing smoking in those sites.

\section{Methods}

SAMPLE

Hospital 1 (H1) was a large, urban teaching hospital of 530 beds selected for the study on the basis of its intention to implement outdoor smoke-free zones. Hospital 2 (H2) was a smaller, rural hospital of 156 beds selected because of its similarity in case mix to hospital 1 .

DESIGN

This observational study first described the type of smoker and the proportion of smokers observed in each location at time 1 . The study then compared the proportion of all smokers, observed in targeted outdoor areas, before and after the introduction of outdoor smoke-free signs, in $\mathrm{H} 1$. Changes from time 1 to time 2 were compared with changes observed in $\mathrm{H} 2$ where no change in outdoor smoking signs occurred.

\section{DESCRIPTION OF OUTDOOR SITES}

On a map of each hospital, the grounds were divided into geographically discrete sites. The sites were not uniform in size, but were rather delineated by the natural borders of the location-for example, a veranda or a courtyard, or a covered passageway. Each site was approximately $10 \mathrm{~m} \times 10 \mathrm{~m}$ in area. Where a geographical area, such as a courtyard, was large, it was divided into two sites. Only outdoor grounds that were up to $50 \mathrm{~m}$ from any entrance or exit to any hospital building were included in the survey. Sites with similar characteristics-for example, verandas-were collectively referred to as a zone. In total, 135 individual sites were mapped in $\mathrm{H} 1$ and 67 in $\mathrm{H} 2$, including the following zones.

- Courtyards: 8 sites (H1) and 3 sites (H2)

- Main entrance (10 m from main entrance): 5 sites $(\mathrm{H} 1)$ and 5 sites $(\mathrm{H} 2)$

- Secondary entrance (10 m from secondary entrances): 8 (H1) and $22(\mathrm{H} 2)$.

- Covered exit passageways: 9 sites (H1) and 2 sites (H2)

- Verandas: 88 sites $(\mathrm{H} 1)$ and 16 sites $(\mathrm{H} 2)$

- Firestairs (internal): 5 sites (H1) and 1 site (H2); (external) 3 sites $(\mathrm{H} 1)$ and 3 sites (H2)

- Pathways ( $>10 \mathrm{~m}$ and $<50 \mathrm{~m}$ from any entrance): 9 (H1) and 7 (H2)

- Lawns/carparks (>10 m and $<50 \mathrm{~m}$ from entrances): 4 (H1) and $8(\mathrm{H} 2)$.

\section{DESCRIPTION OF OUTDOOR SMOKE-FREE SIGNS} Hospital 1

Hospital 1 intended to introduce outdoor smoke-free signs around entrances and on thoroughfares to reduce the problems of litter, poor image, and tobacco smoke being drawn into the hospital air conditioning system. A committee was formed by members of the occupational health and safety team in hospital 1 to coordinate and implement all aspects of the introduction of the new policy. The committee consisted of representatives from the NSW Cancer Council, the National Heart Foundation, hospital management, unions, occupational health and safety, and the first author (whose role was to evaluate the impact of the signs). This committee determined the type and placement of the signs and incorporated the new policy launch into the World No-Tobacco Day activities. These activities were focused around the theme of Clear the Air. All staff were notified of the new policy through newsletters, bulletin boards, and their supervisors. Smoke-free signs were to be introduced into 22 sites in $\mathrm{H} 1$ (16\% of total $\mathrm{H} 1$ sites). All signs in $\mathrm{H} 1$ were to display either the wording "No smoking" or the symbol for no smoking and all signs were to be attached to the outer walls of the buildings.

\section{Hospital 2}

Of the 67 sites mapped in H2, 11 (16\%) already contained smoke-free signs. The signs read "You are now entering a smoke-free environment, please extinguish your cigarette", and were positioned at the entrance to the site and accompanied by an ashtray. Of these 11 sites, two were courtyards, one was a covered exit passageway, one was a pathway, one was a lawn/carpark, three were main entrance sites, and three were secondary entrance sites. 
Table 1 Description of outdoor smokers in both hospitals

\begin{tabular}{lllll}
\hline & \multicolumn{2}{c}{ Hospital 1 } & \multicolumn{2}{c}{ Hospital 2 } \\
\cline { 2 - 5 } & Time 1 (n=593) & Time 2 (n=301) & Time 1 (n=130) & Time 2 (n=148) \\
& $n(\%)$ & $n(\%)$ & $n(\%)$ & $n(\%)$ \\
\hline Staff & $296(50)$ & $140(47)$ & $76(58)$ & $90(61)$ \\
Patients & $62(10)$ & $47(16)$ & $7(5)$ & $9(6)$ \\
Visitors & $235(40)$ & $114(38)$ & $47(36)$ & $49(33)$ \\
\hline
\end{tabular}

OBSERVATION PERIODS

The first data collection period for both hospitals occurred two weeks before the introduction of the outdoor smoke-free signs in $\mathrm{H} 1$, and the second occurred one month after the introduction of the signs in H1. Data collection for both periods was carried out for seven days in each hospital, over a two-week period. Observations of people on the grounds of each hospital were made on seven days at several different time periods each day. One of five possible combinations of hours between 9 am and $6 \mathrm{pm}$ was randomly allocated to each day of the week. At time 1 each hospital was randomly assigned one of two possible Mondays, and so on for each day of the week, thus ensuring a random mix of days of the week and times of the day. Each day contained either four, five, or six observation hours. Observations at time 2 were matched exactly for day and time with those taken during time 1. During an observation hour all sites were visited once. An "observation" refers to the period of counting (about a minute) which occurred at each site during each selected hour on each day of the week.

\section{PROCEDURE}

The nature of the study was not disclosed to staff at the hospitals. Apart from the committee in hospital 1, only the Chief Executive Officer and one other staff member at each hospital knew the exact aims of the study and they consented to total confidentiality. One of two trained observers was randomly allocated to each data collection day. Observers were experienced research assistants who wore street clothes and a University identification badge, and carried a clipboard containing the log sheets and maps. They also carried a letter of introduction to present on request to hospital personnel. This letter explained that the purpose of the study was to conduct a survey of people's usage patterns of outdoor areas. The observer began at a predetermined start point at the first observation hour of the day and walked by a predetermined route around the hospital, taking about an hour. Each site was identified visually on the map by a numerical code and a colour and was also described in narrative form on the data log. All sites in each zone-for example, all verandas-were given the same colour code on the maps. Each individual site was either walked through, or was visible from the route. The observer unobtrusively recorded the data on the log sheet, as the route was traversed. The count was done by either visually scanning from left to right across a large or a distant site, or by coding each individual as the observer passed by them while walking through the site.

\section{MEASURES}

Weather

At each observation hour the weather was clas 음 sified as either fine or rainy. Because of the impact of rainy weather on outdoor usage of sites, observation hours classified as rainy were excluded.

\section{Smokers}

Children under the age of 12 were not included in the count. Each individual observed in particular site was entered onto the data $\log$ as either a "smoker" (anyone who was eithero lighting, stubbing out, or smoking a cigarette $\vec{\bullet}$ pipe or cigar) or a "non-smoker". Within these two categories people were further classified as either "staff" (anyone wearing a uniform, or के hospital identification badge, or carrying $\dot{x}$ stethoscope), "patient" (wearing night wear, or a hospital gown, or a patient wrist band) of "visitor" (those not classified as staff oro patient).

\section{Reliability}

Measures of reliability were made before the start of data collection by comparing the data from two circuits of each hospital made simultaneously and independently by bothe observers. They counted the number of people in each site and classified them as either a smoker or non-smoker and as either staffs patient, or other. Thus each person observeco had one of six possible coding categories Inter-observer reliability was calculated as the total number of agreements divided by the sum $\overrightarrow{\vec{\sigma}}$ of the total number of agreements and the tota $B$ number of disagreements multiplied by $100 \mathrm{Z}$ Inter-observer reliability was assessed before. the start of the study and was based on observations of 404 sites (135 sites in $\mathrm{H} 1 \times 2$ circuitso and 67 sites in $\mathrm{H} 2 \times 2$ circuits). A total of 1600 people were observed during these circuits. There were 2424 potential points of agreement (404 sites $\times 6$ categories) and reliability was $98.5 \%$.

\section{ANALYSIS}

\section{Smoking rate}

The incidence of smoking on the grounds of the two hospitals at times 1 and 2 waso calculated by the number of people observed smoking as a proportion of all people observedo on the grounds.

\section{Description of outdoor smokers}

At times 1 and 2 the number of smokers fied as either staff, patient, or visitor was calculated as a proportion of all the smokers? observed on the grounds at that time.

\section{Location of smokers}

The number of smokers at time 1 who wereo observed in each geographical zone was calcu lated as a proportion of all smokers observed on the grounds.

\section{Effectiveness of outdoor smoke-free signs}

To determine whether the introduction of outdoor smoke-free signs in certain sites in $\mathrm{H} 1$ was effective in reducing smoking in these 
Table 2 Location of outdoor smokers in both hospitals

\begin{tabular}{|c|c|c|c|c|}
\hline \multirow[b]{2}{*}{ Zones } & \multicolumn{2}{|c|}{ Hospital 1} & \multicolumn{2}{|c|}{ Hospital 2} \\
\hline & $\begin{array}{l}\text { Time } 1(n=593) \\
n(\%)\end{array}$ & $\begin{array}{l}\text { Time } 2(n=301) \\
n(\%)\end{array}$ & $\begin{array}{l}\text { Time } 1(n=130) \\
n(\%)\end{array}$ & $\begin{array}{l}\text { Time } 2(n=148) \\
n(\%)\end{array}$ \\
\hline \multicolumn{5}{|c|}{ Within $10 \mathrm{~m}$ of entrances or exits } \\
\hline Courtyards & $288(49)$ & $138(46)$ & $30(23)$ & $32(27)$ \\
\hline Main entrances & $142(24)$ & $68(23)$ & $10(7)$ & $11(7)$ \\
\hline Secondary entrances & $41(7)$ & $28(9)$ & $45(35)$ & $56(38)$ \\
\hline Verandas & $5(1)$ & $2(1)$ & $14(11)$ & $33(22)$ \\
\hline Covered Exit Passageways & $8(1)$ & $10(3)$ & $0(0)$ & $0(0)$ \\
\hline Fire Stairs (internal) & $0(0)$ & $0(0)$ & $0(0)$ & $0(0)$ \\
\hline Fire Stairs (external) & $0(0)$ & $1(0)$ & $19(14)$ & $6(4)$ \\
\hline Total & $(82)$ & (82) & $(90)$ & $(93)$ \\
\hline \multicolumn{5}{|c|}{$\begin{array}{l}\text { More than } 10 \mathrm{~m} \text { and less than } 50 \mathrm{~m} \text { from entrances } \\
\text { and exits }\end{array}$} \\
\hline Pathways & $96(16)$ & $41(14)$ & $6(5)$ & $1(1)$ \\
\hline Lawns/carparks & $13(2)$ & $13(4)$ & $6(5)$ & $2(1)$ \\
\hline Total & (18) & (18) & (10) & (7) \\
\hline
\end{tabular}

sites, we measured the percentage of all outdoor smokers who were observed smoking in these targeted sites, in both hospitals, before and after the introduction of the signs in $\mathrm{H} 1$. Any changes from pre-test to post-test in $\mathrm{H} 1$ were compared with changes from pre-test to post-test in $\mathrm{H} 2$.

\section{Results}

OBSERVATION PERIODS

A total of 4451 observations were made in $\mathrm{H} 1$ and 2479 observations in $\mathrm{H} 2$ at times 1 and 2 (calculated by number of sites $x$ number of observation hours $\times$ number of study days).

\section{WEATHER}

Five per cent of $\mathrm{H} 1$ observations and $3 \%$ of $\mathrm{H} 2$ observations at pre-test occurred during rainy weather. At post-test, $37 \%$ of $\mathrm{H} 1$ observations and $22 \%$ of $\mathrm{H} 2$ observations occurred during rainy weather. As observations made during rainy weather could differentially affect the number of smokers and non-smokers in outdoor uncovered sites, all observations taken during rainy weather were excluded from the study. At time 1, $4252 \mathrm{H} 1$ observations and $2414 \mathrm{H} 2$ observations remained in the sample. At time 2, $2787 \mathrm{H} 1$ observations and $1943 \mathrm{H} 2$ observations remained in the sample.

\section{SMOKING RATE}

At time 1, a total of 1926 people were observed in all the mapped outdoor sites in $\mathrm{H} 1$ and 845 people in $\mathrm{H} 2$, of whom 595 (31\%) and 130 $(15 \%)$, respectively, were observed smoking. At time 2, a total of 902 people were observed on the grounds of $\mathrm{H} 1$ and 536 people in $\mathrm{H} 2$, of whom $301(33 \%)$ and $148(28 \%)$, respectively, were observed smoking.

Table 3 Outdoor smokers in smoke-free amd smoking areas

\begin{tabular}{|c|c|c|c|c|c|}
\hline & Time 1 & Time 2 & & & \\
\hline & $\overline{n / \text { total } n(\%)}$ & $\overline{n / \text { total } n(\%)}$ & $\chi^{2}$ & $d f$ & $P$ \\
\hline \multicolumn{6}{|l|}{ Hospital $1^{\star}$} \\
\hline Smoke-free areas & $105 / 593(32)$ & $83 / 301(28)$ & & & \\
\hline Smoking areas & $488 / 593(68)$ & $218 / 301(72)$ & 11.71 & 1 & 0.001 \\
\hline \multicolumn{6}{|l|}{ Hospital 2} \\
\hline Smoke-free areas & $62 / 130(48)$ & $68 / 148(46)$ & & & \\
\hline Smoking areas & $68 / 130(52)$ & $80 / 148(54)$ & 0.09 & 1 & 0.771 \\
\hline
\end{tabular}

* Smoking was allowed in all outdoor areas in Hospital 1 at Time 1

Smoke-free areas refer to areas that became smoke-free at Time 2 .

\section{DESCRIPTION OF OUTDOOR SMOKERS}

Table 1 shows the percentage of outdoor smokers who were classified as "staff", "patient", or "visitor. Patients were found to represent the smallest group of outdoor smokers, ranging from $5-16 \%$ of all smokers. Staff constituted between $47 \%$ and $61 \%$ of all outdoor smokers, whereas visitors represented $33-40 \%$ of people observed smoking outdoors. The proportions of smokers who were staff, patients, or visitors did not differ significantly between the two hospitals at time $1\left(\chi^{2}=4.72\right.$, $\mathrm{df}=2, \mathrm{P}<0.095)$. However, there was a significant difference at time $2\left(\chi^{2}=11.81, \mathrm{df}=2\right.$, $\mathrm{P}<0.003)$, with a greater proportion of smokers being staff at $\mathrm{H} 2$ compared with $\mathrm{H} 1$ $(61 \%$ vs $47 \%)$, although absolute percentages did not vary greatly between times 1 and 2 at each hospital.

\section{LOCATION OF OUTDOOR SMOKERS}

Table 2 shows the percentage of all outdoor smokers observed in each of the geographical zones at times 1 and 2 in both hospitals.

In $\mathrm{H} 1$, courtyards and main entrances were the most popular smoking locations (73\%) at time 1 and at time $2(69 \%)$, whereas in $\mathrm{H} 2$, where more than half of these courtyard and main entrance sites were designated as smokefree, only $30 \%$ (at time 1) and $34 \%$ (at time 2 ) of all outdoor smokers were located in these sites. In the main entrance site in $\mathrm{H} 2$, for example, clear geographical boundaries existed and the smoke-free signs were positioned at all entries to the area with the wording "You are now entering a smoke-free zone, please extinguish your cigarette". Only $7 \%$ of all outdoor smokers were observed in this main entrance location in $\mathrm{H} 2$ (at times 1 and 2).

Zones within $10 \mathrm{~m}$ of an entrance to the hospital building were most popular in both hospitals ( $82 \%$ of all outdoor smokers in $\mathrm{H} 1$ at times 1 and 2) and $90 \%$ and $93 \%$ (at times 1 and 2 , respectively) of all outdoor smokers in $\mathrm{H} 2$ ).

EFFECTIVENESS OF INTRODUCTION OF OUTDOOR SMOKE-FREE SIGNS

Table 3 shows that those outdoor sites selected by the committee in $\mathrm{H} 1$ to become smoke-free were used by $32 \%$ of all outdoor smokers at 
time 1 and by $28 \%$ at post-test (4-percentage point decrease, $\mathrm{P}<0.001$ ). In $\mathrm{H} 2$, the percentage of all outdoor smokers in the smoke-free sites was $48 \%$ at time 1 and $46 \%$ at time 2 (difference not significant).

\section{Discussion}

Overall the findings of this study suggest that the introduction of outdoor smoke-free signs may be an effective strategy in reducing but not eliminating smoking around entrances and exits of public hospitals, at least in the immediate period following the introduction of the bans. However the results need to be interpreted cautiously, due to a number of methodological limitations to the study. Firstly, observations from only two hospitals are reported, so it is unclear whether the findings can be generalised. Secondly, the impact of introducing outdoor smoke-free zones was observed in only one hospital. The poorer level of compliance with outdoor smoke-free zones at times 1 and 2 in hospital 2 suggests that compliance may be a problem after the initial impact of the introduction of smoke-free sites, and effective maintenance strategies may need to be considered. This is consistent with research in other areas of tobacco control such as sales to minors, which suggests that strategies such as placement of signs and education of retailers are not adequate without good enforcment of the policy. ${ }^{19}$ A further limitation is the reduced number of observation periods at time 2 because of rainy weather and the fact that a greater proportion of observations was lost from $\mathrm{H} 1$ due to rain. This may have biased the results by changing the patterns of smoking to a greater extent in H1 compared with H2. Finally, the control hospital was selected as the closest match to the main hospital, but varies in a number of ways including size and geographical location. Despite these limitations, the study presents some unique findings on the pattern of smoking behaviour in outdoor hospital sites.

\section{TYPES OF SMOKERS}

The finding that staff and visitors make up $90 \%$ of the observed outdoor smokers implies that implementation and compliance strategies should specifically target staff and visitors. Other researchers have found that the introduction of internal bans did not reduce the prevalence of smoking among hospital staff. $^{713}$ Rather than acting as exemplars of non-smoking behaviour, staff are currently providing a visual message to the community that smoking is acceptable. ${ }^{20}$ Staff education could stress their responsibilities for patient care, the importance of role modelling, and the role of the hospital in public health issues. The implementation of new staff recruiting guidelines, stating a clear preference for non-smokers, would reduce the problem in the future, and smoking cessation or "working without tobacco" programmes offered to staff may help to reduce the problem. Dawley et al found that smoke-free signs inside the hospital buildings without education of staff and compliance enhancement strategies were ineffective in preventing smoking. ${ }^{3}$ Highly visible signs at hospital drive-in entrances, exits from all carparks, all pathways leading to the hospital, and on the hospital grounds, coulक provide information about the smoke-free policy. Staff could be made aware of the reasons for the policy, likely enforcement of the policy, and the location of support services through newsletters and payslips. A smoke-free hospital has been reported by patients as the most appropriate way to highlight the danger of smoking. ${ }^{12}$

LOCATION OF SMOKERS

The literature has provided anecdotal reports of the "migration of smokers", as a result of internal smoking restrictions in the hospitaț setting. ${ }^{3}$ Our study found a marked clustering of smokers around hospital entrances at time 1 with $82 \%$ and $90 \%$ (in $\mathrm{H} 1$ and $\mathrm{H} 2 \mathrm{\varrho}^{\circ}$ respectively) of all observed outdoor smokers being located within $10 \mathrm{~m}$ of an entrance or exit to the building. This concentration of smokers at main entrances and exits create? problems of environmental tobacco smoke (ETS), increased litter, fire risk, and negative्ष role modelling by staff in the most highlyvisible and used areas. ${ }^{516}$

EFFECTIVENESS OF SIGNS

The finding that the introduction of "No smoking" signs in hospital 1 reduced the proportion of outdoor smokers in these sites io encouraging, although the overall decrease was small in absolute terms. It would seem that $\overrightarrow{\vec{Q}}$ although it is possible to reduce smoking in outdoor hospital sites with the erection of signs, compliance is still far from optimal. The lack of clear geographical boundaries indicating the beginning and end of outdoof smoke-free sites creates special difficulties foß̂ implementing outdoor smoke-free zones. In hospital 1, where the signs were mounted on an external wall, with the wording "No smoking"을 much ambiguity was possible as to whether the signs referred to the buildings or to the externa $\bar{b}$ environment. In hospital 2, clear geographicap boundaries existed, particularly outside the main entrance, and smoke-free signs were positioned at all entries to the area with theo wording "You are now entering a smoke-free zone, please extinguish your cigarette". Such wording leaves little room for ambiguity and is reflected in the small number of outdoot smokers observed in this area $(8 \%)$.

\section{FUTURE POLICY IMPLICATIONS}

Our study suggests that the introduction of outdoor smoke-free signs, defining some areas as smoking and other areas as smoke-free, may他 yield a small reduction in the proportion of smokers in these sites, but is not effective in eliminating smoking. Furthermore, the findings from $\mathrm{H} 2$ suggest that compliance with the bans may not improve over time. The advantage of policy introduction is that it cam enable gradual movement towards a totally smoke-free hospital site. It affords an opportunity to develop and implement other initiatives in education, staff training, cessation 
support, compliance enhancement, and enforcement strategies. Other researchers have suggested that successful smoke-free policies should be introduced gradually to maintain the productivity and morale of staff. ${ }^{13}$

There are clear economic benefits associated with the introduction of a total smoke-free hospital site policy, including reduced risk from fire, ${ }^{16}$ greater productivity among employees, reduced sickness and absenteeism, and lower cleaning costs. ${ }^{5}$ Given the current accumulation of smokers around the entrances and coutyards of hospitals, such a policy would serve to protect other people entering the hospital from ETS as well as preventing the ETS from being drawn into the indoor hospital environment through open doors and windows. Other less tangible, yet perhaps more powerful benefits of a totally smoke-free hospital, exist in the sending of a clear message to the community that smoking is incompatible with the mission and public image of a healthcare organisation, ${ }^{5}$ that cigarettes are sufficiently harmful to warrant control within this setting, and that smokers are expected to and capable of resisting the urge to smoke while on the hospital site.

Public hospitals in Australia are well placed to move towards totally smoke-free hospital sites. Such a move would convey, to the community, that health departments and hospital management no longer tolerate a health risk behaviour estimated to cost $\mathrm{A} \$ 144$ million in direct in-patient costs in NSW each year, ${ }^{21}$ and to cause 18000 deaths in the nation annually. ${ }^{22}$ Based on current rates of 2000 staff, 25000 inpatients, and about 100000 visitors per year in $\mathrm{H} 1$ alone, the number of smokers in this one hospital affected by such an outdoor smoke-free policy would be approximately 600 staff, 850 patients, and 25000 visitors per year. If such figures were to be extrapolated to all hospital settings in Australia, the potential population impact on smoking behaviour and exposure to ETS would be highly significant. Such moves are required if we are to adopt a smoke-free society by the year 2000 as promoted by C Everett Koop when he was US Surgeon General. ${ }^{23}$

This research was undertaken by the NSW Cancer Council Cancer Education Research Program team, directed by Professor R Sanson-Fisher. The views expressed are not necessarily those of the NSW Cancer Council. The authors would like to thank the hospital staff at Maitland and John Hunter Hospitals for their support of this project, Rob Sanson-Fisher and Michael Hensley for their advice, and Stephen Halpin for statistical support.

1 Dawley HH, Burton MC. Smoking control in a hospital setting. Addict Behav 1985;10:351-5.

2 Barker AF, Moseley JR, Glidewell BL. Components of a smokefree hospital setting. Arch Int Med 1989;149:1357-9.

3 Dawley HH, Morrison J, Carrol S. Compliance behaviour in a hospital setting: Employee and patient reactions to no-smoking signs. Addict Behav 1980;5:329-31.

4 US Department of Health and Human Services. The health consequences of involuntary smoking. A report of the Surgeon General, 1986. Rockville, Maryland: Public Health Service, Centers for Disease Control, 1986. (DHHS Publication No (CDC) 87-8398.)

5 Fielding JE. Banning worksite smoking. Am f Public Health 1986;76:957-9.

6 Burtaine J, Slade J. The smokefree hospital. NF Med 1988;85:143-5.

7 Rigotti NA. Trends in the adoption of smoking restrictions in public places and worksites. New York $\mathcal{F}$ Med 1989;89:19-26.

8 Kelly NR, Cohen FL. Smoking policies in US hospitals: current status. Prev Med 1979;8:557-61.

9 Becker DM, Conner HF, Waranch HR, et al. The impact of a total ban on smoking in the Johns Hopkins Children's Center. $\mathcal{F} A M A$ 1989;262:799-802.

10 Longo DR, Brownson RC, Kruse RL. Smoking bans in US hospitals: results of a national survey. $\mathscr{f} A M A$ 1995; 274:488-91.

11 Directorate of the Drug Offensive. Policy on smoke-free working environment. 1988; (Internal circular) NSW Department of Health, CEIDA Private Mail Box 6, PO Rozelle, New South Wales, Australia.

12 Kottke TE, Hill C, Hertzig C, et al. Smokefree hospitals: Attitudes of patients, employees, and faculty. Minn Med 1985;68:53-5

13 Rosenstock IM, Stergachis A, Heaney C. Evaluation of smoking prohibition policy in a health maintenance organization. Am F Public Health 1986;76:1014-5.

14 Mullooly JP, Schuman KL, Stevens VJ, Glasgow RE, Vogt TM. Smoking behaviour and attitudes of employees of a large HMO before and after a worksite ban on cigarette large HMO before and after a worksite ba
smoking. Public Health Rep 1990;105:623-8.

15 Biener L, Abrams DB, Follick MJ, Dean L. A comparative evaluation of a restrictive smoking policy in a general hospital. Am ₹ Public Health 1989;79:192-5.

16 Stillman F, Becker DM, Swank R, et al. Ending smoking at the John Hopkins Medical Institutions-and evaluation of smoking prevalence and indoor air pollution. $\mathscr{f} A M A 1990$; 264:1565-9.

17 Joseph AM, Knapp JM, Nichol KL, Pirie PJ. Determinants of compliance with a national smoke-free hospital standard. $尹$ A $M A$ 1995;274:491-4.

18 Hurt $\mathrm{RD}$, Berge $\mathrm{KG}$, Offord $\mathrm{KP}$, et al. The making of a smokefree medical centre. $\mathcal{F A M A} 1989 ; 261: 95-7$.

19 DiFranza JR. Active enforcement of minors' access laws: a moral and ethical imperative. Tobacco Control 1995;4:5.

20 Dawley HH. The discouragement of smoking in a hospital setting: the importance of modeled behaviour. Int $\mathscr{f}$ Addict 1981;16:905.

21 Dickman P, Gibberd R. The estimation of tobacco and alcoholcaused hospital admissions and their inpatient costs in N.S.W. hospitals 1988/89. Report No. 3. Newcastle, New South Wales: NSW Health Services Research Group, 1990.

22 Commonwealth Department of Community Services and Health. Tobacco in Australia. A summary of related statistics. Canberra, ACT: Australian Government Publishing Service, 1988 .

23 Koop CE. A smoke-free society by the year 2000. NY State f Med 1985;85:290-2. 